\title{
Likelihood of rapidly increasing surface temperatures unaccompanied by strong warming in the free troposphere
}

\author{
T. N. Chase ${ }^{1, *}$, R. A. Pielke $\mathrm{Sr}^{2}$, B. Herman ${ }^{3}$, X. Zeng ${ }^{3}$ \\ ${ }^{1}$ Cooperative Institute for Research in Environmental Sciences, University of Colorado, Boulder, Colorado 80309, USA \\ ${ }^{2}$ Department of Atmospheric Science, Colorado State University, Ft. Collins, Colorado 80523, USA \\ ${ }^{3}$ Department of Atmospheric Sciences, University of Arizona, Tucson, Arizona 85721, USA
}

\begin{abstract}
Recent model simulations of the effects of increasing greenhouse gases combined with other anthropogenic effects predicted larger rates of warming in the mid and upper troposphere than near the Earth's surface. In multiple model comparisons we find that accelerated upper-level warming is simulated in all models for the greenhouse-gas/direct-aerosol forcing representative of 1979-2000. However, in a test of model predictive skill, a comparison with observations shows no warming of the free troposphere over this period. We assessed the likelihood that such a disparity between model projection and observations could be generated by forcing uncertainties or chance model fluctuations, by comparing all possible $22 \mathrm{yr}$ temperature trends in a series of climate simulations. We find that it is extremely unlikely for near-surface air temperatures (surface temperatures) to increase at the magnitude observed since 1979 without a larger warming in the mid-troposphere. Warming of the surface relative to the mid-troposphere was also more likely in control simulations than under anthropogenic forcing. Because errors in the vertical temperature structure would be expected to create errors in water-vapor feedback, cloud cover and moisture content, these results suggest the need for great caution when applying the simulations to future climate predictions and to impact assessments.
\end{abstract}

KEY WORDS: Climate change $\cdot$ Model assessment $\cdot$ Vertical temperature structure

\section{INTRODUCTION}

An observed increase in global surface temperatures since 1979 has been most strongly tied to human activity by the IPCC (2001), and it is hypothesized to continue upwards as a result of increasing greenhousegas concentrations. Climate-model simulations indicate increasing surface temperatures in rough agreement with observations. An important test of model predictive ability and usefulness for impact studies is how well models simulate the observed vertical temperature structure of the troposphere under anthropogenically-induced-change scenarios.

Recent climate-model simulations produce a larger warming in the free troposphere than at the surface when forced by increasing atmospheric greenhouse- gas concentrations and the direct effect of sulfate aerosols (IPCC 1996, 2001). Fig. 1 shows example time series of global average surface temperature and $500 \mathrm{mb}$ temperature changes resulting from $\mathrm{CO}_{2}$ and aerosols simulated by a single realization from each of the 4 coupled atmosphere-ocean climate models: the CGCM1 and CGCM2 from the Canadian Centre for Climate Modelling and Analysis (CCCma; Flato et al. 2000; Flato and Boer, 2001), the Goddard Institute for Space Studies (GISS; Russel et al. 2000) coupled atmosphere-ocean model and the Geophysical Fluid Dynamics Laboratory (GFDL; Delworth et al., 2002) model. Each shows accelerated warming at $500 \mathrm{mb}$ relative to the surface. Details of each simulation suite are given in Table 1. This pattern is a general feature of climate models and is also produced in more comprehen- 

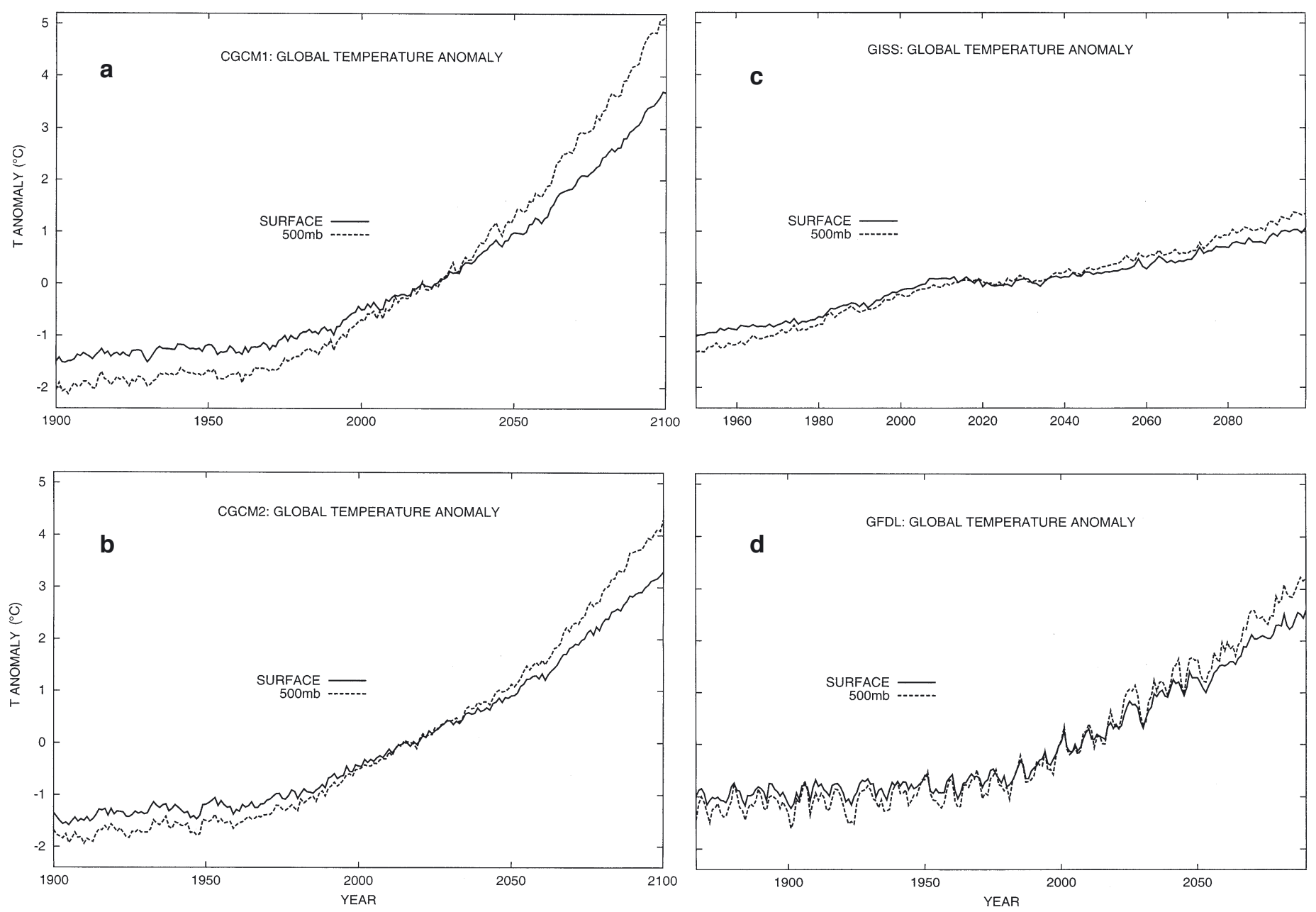

Fig. 1. Globally averaged surface and $500 \mathrm{mb}$ temperature anomalies (relative to the 1979-2000 mean) for 1 realization of: (a) the Canadian Center for Climate Modelling and Analysis coupled model I (CGCM1) ensemble, (b) CGCM2, (c) the Goddard Institute for Space Studies (GISS) model, and (d) the Geophysical Fluid Dynamics Laboratory (GFDL) model

sive climate-change simulations (Roeckner et al. 1999). Though many climate forcings and feedbacks are not accounted for in these simulations, similar forcing assumptions are the basis of both the IPCC (2001) report and the US National Assessment (National Assessment Synthesis Team 2001), making a comprehensive examination of performance under these assumptions imperative.
In comparison, a comprehensive analysis of observed temperature changes during 1979-2000 has been provided by the IPCC (2001) assessment report (their Table 2.3). This analysis indicates a strong and significant surface warming of 0.14 to $0.16^{\circ} \mathrm{C}$ decade $^{-1}$ since 1979 in observational data. However, observed temperature trends in the lower troposphere from 5 different data sets range from -0.03 to $+0.04^{\circ} \mathrm{C}$ decade $^{-1}$, are

Table 1. Summary of model simulations

\begin{tabular}{|lccll|}
\hline Model & Duration & Realizations & \multicolumn{1}{c|}{$\mathrm{CO}_{2}$} & Aerosol source \\
\hline CGCM1 & $1900-2100$ & 3 & OBS to 1996, 1\% $\mathrm{yr}^{-1}$ after & Langner \& Rodhe (1991) \\
CGCM2 & $1900-2100$ & 3 & OBS to 1996, 1\% $\mathrm{yr}^{-1}$ after & Langner \& Rodhe (1991) \\
GISS & $1950-2100$ & 2 & OBS to 1990, 0.5\% $\mathrm{yr}^{-1}$ after & Mitchell et al. (1995) \\
GFDL & $1866-2090$ & 3 & IS92a to 1990, 1\% $\mathrm{yr}^{-1}$ after & Haywood et al. (1997) \\
\hline
\end{tabular}


statistically indistinguishable from zero in each measure, and give no indication of warming whatsoever. A revised version of the Microwave Sounding Unit (MSU) satellite data (Mears et al. 2003) indicates a larger tropospheric warming than the original version (Christy et al. 2000) or any of the other datasets discussed in IPCC (2001); reasons for this difference are the subject of vigorous debate (Santer et al. 2003). Recently, Christy et al. (2003) demonstrated a strong correspondence between their version of the MSU time series and several other independent measures of tropospheric temperature trends, and they conclude that the Mears et al. (2003) trend is likely too strong. We address the implications of this alternate satellite data further in the conclusions.

For comparison with trends presented later, Fig. 2 shows the time series for some of these observational data, while Table 2 provides estimated linear trends and significance values. Autocorrelation is corrected for in the estimated trends using an autoregressive error model for up to 4 time lags using a stepwise procedure testing for autocorrelation at each lag. When the strong El Niño year of 1998 is removed from near the end of the time series, all upper-level airtemperature measurements show weak and insignificant cooling during 1979-2000 (Table 2). There appears to be little evidence for a progressive warming above the surface since 1979.

It is unclear from IPCC (2001) and from Fig. 1 whether model-projected accelerated warming aloft should be detectable at the present time. Therefore, our first objective was to assess whether any simulated accelerated warming aloft was of sufficient magnitude to be presently detectable.

Table 2. Linear regression trends $\left({ }^{\circ} \mathrm{C}\right.$ decade $\left.^{-1}\right)$ and significance $\mathrm{p}$ values in parentheses for 3 upper-level air-temperature datasets and the surface for 1979-2000 and with the strong El Niño year of 1998 removed. SFC: Jones et al. (2001); NCEP: Kalnay et al. (1996); MSU: Christy et al. (2000); RAWINSONDE: Sterin (2001)

\begin{tabular}{|lccc|}
\hline SFC & NCEP $(500 \mathrm{mb})$ & MSU 2LT-d & $\begin{array}{c}\text { RAWINSONDE } \\
(850-300 \mathrm{mb})\end{array}$ \\
\hline $\begin{array}{l}\text { All data } \\
0.16(<0.01)\end{array}$ & $0.01(0.85)$ & $0.04(0.51)$ & $-0.00(0.92)$ \\
$\mathbf{1 9 9 8}$ removed & $-0.04(0.43)$ & $-0.01(0.81)$ & $-0.04(0.24)$ \\
\hline
\end{tabular}

Our second objective was to examine all possible 22 yr time series in the climate-change and control simulations and assess the likelihood that such a disparity between predicted and observed patterns of warming could result from model variability or small uncertainties in forcing rates.

\section{SIMULATED SURFACE VERSUS TROPOSPHERIC TEMPERATURE, 1979-2000}

Table 3 gives the 1979-2000 surface and $500 \mathrm{mb}$ temperature trends for each model realization calculated from linear regression model corrected for autocorrelation. We chose 1979-2000 to examine in detail for several reasons. Satellite observations became available in 1979, allowing a comprehensive picture of free troposphere temperature changes. It is unclear whether trends from the NCEP Reanalysis prior to 1979 are homogeneous (Santer et al. 1998). The very large observed surface warming beginning in the late 1970s has been tied, in large part, to anthropogenic causes by the IPCC (2001) report. This is therefore the period when comparisons with model simulations of anthropogenically induced effects should be most informative.

For the simulated period, 1979-2000, all models exhibited a significant $(p<0.001)$ warming at the 
Table 3. Linear regression trends $\left({ }^{\circ} \mathrm{C}\right.$ decade $\left.{ }^{-1}\right)$ for model simulations over $1979-2000 . \mathrm{p}<0.01$ for all trends

\begin{tabular}{|c|c|c|c|c|c|c|c|c|c|c|c|}
\hline \multirow[b]{2}{*}{ Realization } & \multicolumn{3}{|c|}{ CGCM1 } & \multicolumn{3}{|c|}{ CGCM2 } & \multicolumn{2}{|c|}{ GISS } & \multicolumn{3}{|c|}{ GFDL } \\
\hline & 1 & 2 & 3 & 1 & 2 & 3 & 1 & 2 & 1 & 2 & 3 \\
\hline Surface & 0.25 & 0.25 & 0.26 & 0.29 & 0.27 & 0.24 & 0.22 & 0.20 & 0.28 & 0.23 & 0.20 \\
\hline $500 \mathrm{mb}$ & 0.31 & 0.37 & 0.35 & 0.35 & 0.37 & 0.32 & 0.26 & 0.25 & 0.28 & 0.24 & 0.27 \\
\hline Ratio & 1.24 & 1.48 & 1.36 & 1.22 & 1.36 & 1.35 & 1.19 & 1.26 & 0.98 & 1.05 & 1.35 \\
\hline
\end{tabular}

surface ranging from 0.20 to $0.29^{\circ} \mathrm{C}$ decade $^{-1}$. All models also simulate a significant $(\mathrm{p}<0.001) 500 \mathrm{mb}$ warming (from $0.29-0.37^{\circ} \mathrm{C}$ decade ${ }^{-1}$ ) which exceeded the trend at the surface in all except 1 realization of the GFDL model, where the trends were comparable. On average, the surface trend among the 11 model realizations considered here was $0.24^{\circ} \mathrm{C}$ decade $^{-1}$, while the average $500 \mathrm{mb}$ temperatures increased $0.06^{\circ} \mathrm{C}$ decade $^{-1}$ (or $25 \%$ ) faster than at the surface. This difference is more than one-third the total observed surface trend and should be detectable.

\section{COMPARISON OF SURFACE AND $500 \mathrm{mb}$ TRENDS IN CLIMATE-CHANGE SIMULATIONS}

While the model evidence in the preceding section indicates that it is highly unlikely for a climate dominated by increasing greenhouse gases and the direct aerosol effect to warm at the surface and not warm at a faster (or at least comparable) rate aloft, it is possible that such a situation may occur at times due to some combination of internal model variability or variations in forcing. We therefore examined all possible $22 \mathrm{yr}$ surface trends using a simple linear regression model in each of the simulations for a warming rate which is at least that observed $\left(0.16^{\circ} \mathrm{C}\right.$ decade $\left.{ }^{-1}\right)$ and compared with the corresponding trend at $500 \mathrm{mb}$. We searched for evidence that it is possible, under some circumstances, for a model to warm quickly at the surface but not at $500 \mathrm{mb}$. We maximized the chance that a warming is statistically significant and therefore detectable by using a simple linear regression model for this analysis.

A total of 1018 periods of 22 yr across all realizations of all 4 models met the surface warming criterion of a $0.16^{\circ} \mathrm{C}$ decade ${ }^{-1}$ warming. Of these periods, 987 (97\%) had a larger warming at $500 \mathrm{mb}$ than at the surface (Table 4). While all models had a large proportion of periods with larger warming aloft than at the surface, there are also clear differences in the statistics between models. For example, both CCCma models had 500 mb-level warming faster than at the surface in every 22 yr period, while the GFDL simulations had the largest proportion of surface trends exceeding the $500 \mathrm{mb}$-level trends ( $23 \%$ of the cases).
Table 4. Fraction of simulated 22 yr periods with strong surface warming where the $500 \mathrm{mb}$ temperature trend exceeded the surface temperature trend

\begin{tabular}{|lcccc|}
\hline & CGCM1 & CGCM2 & GISS & GFDL \\
\hline Surface & $338 / 338$ & $336 / 336$ & $86 / 111$ & $290 / 312$ \\
\hline
\end{tabular}

Of the $3 \%$ of cases where the surface warmed faster than at $500 \mathrm{mb}$, there was most often a comparable warming at $500 \mathrm{mb}$. However, 3 instances where the surface warmed significantly $(p<0.1)$ and substantially (defined here as $>1.3$ times the $500 \mathrm{mb}$ warming) were recorded with the maximum ratio of surface-to-500 mblevel warming at 1.37 , as compared to the observed ratio of at least 4.0 times faster warming at the surface than aloft. There was no indication of significantly increased probability of accelerated surface warming late in a simulation under stronger forcing.

\section{COMPARISON OF SURFACE AND $500 \mathrm{mb}$ TRENDS IN CONTROL SIMULATIONS}

Though we found little evidence that greatly accelerated surface warming is more likely early in climatechange simulations (i.e. in more control-like situations), it is possible that such a situation is more representative of an unforced climate system. Control simulations allow no changes in atmospheric or other forcings over time and give some indication of natural climate variability in the absence of other influences. Control simulations were available for CGCM1, GISS and GFDL, and we examined these for signs that accelerated trends at the surface relative to at $500 \mathrm{mb}$ are possible or become more likely under naturally varying conditions. We began again with any periods with a $0.16^{\circ} \mathrm{C}$ decade $^{-1}$ surface warming and compared to corresponding $500 \mathrm{mb}$ trends. In 9 cases, the 22 yr surface trend exceeded $0.16^{\circ} \mathrm{C}$ decade ${ }^{-1}$; 8 of these 9 cases occured in the GISS model, a manifestation of a warming drift in the control simulation (Russell et al. 2000). All 8 trends in the GISS model, warmed more at the surface than the $500 \mathrm{mb}$ level, with a maximum ratio of 1.2. 
We also compared all surface trends exceeding $0.08^{\circ} \mathrm{C}$ decade ${ }^{-1}$ with $500 \mathrm{mb}$-level trends. All 3 models had surface trends of this magnitude, so this is a more representative sample. Of 84 trends recorded at the surface which exceeded $0.08^{\circ} \mathrm{C}$ decade $^{-1}, 37$ of them warmed faster at $500 \mathrm{mb}(44 \%)$. Of the 47 periods where the surface warmed faster than at $500 \mathrm{mb}$, in 6 of these the trends at the surface were more than 1.3 times larger than at $500 \mathrm{mb}$ and the maximum ratio of surface-to-500 mb-level trends was 1.7. There appears to be some evidence that surface trends exceeding those in the mid-troposphere are more likely under unforced conditions in these models.

\section{DISCUSSION AND CONCLUSIONS}

Because there are claims that the anthropogenic greenhouse-gas warming signal has been detected since the mid-1970s (IPCC 2001), it is important to critically assess model performance and predictive ability as to tropospheric temperature structure during this time period despite its short duration. IPCC (2001) indicated that observed trends for 1979-2000 show no evidence of significant warming in the free troposphere in conjunction with a very large observed warming at the surface. The difference between a troposphere that warms increasingly with height through a deep layer, as in model simulations, and one where warming is confined to a shallow layer near the surface, as in observations, has large implications for atmospheric moisture content, water-vapor feedback, thickness gradients and convection-initiated circulation responses. To determine whether such a disparity could be explained by natural model variability or small changes in forcing, we examined realizations from 4 climate models in both unforced control scenarios and scenarios forced with increased atmospheric greenhouse gasses and the direct aerosol effect. These comparisons indicate the following:

- Model simulations of the period representative of the greenhouse-gas and aerosol forcing for 1979-2000 generally show a greatly accelerated and detectable warming at $500 \mathrm{mb}$ relative to the surface $\left(\mathrm{a} 0.06^{\circ} \mathrm{C}\right.$ decade $^{-1}$ increase).

- Considering all possible simulated 22 yr trends under anthropogenic forcing, a strong surface warming was highly likely to be accompanied by accelerated warming at $500 \mathrm{mb}$ with no change in likelihood as forcings increased over time.

- In simulated periods where the surface warmed more quickly than $500 \mathrm{mb}$, there was never a case in which the $500 \mathrm{mb}$ temperatures did not also warm at a large fraction of the surface warming. A $30 \%$ acceleration at the surface was the maximum simu- lated as compared with an observed acceleration factor of at least $400 \%$ the mid-troposphere trend.

- In cases where there was a strong surface warming and the surface warmed more quickly than at $500 \mathrm{mb}$ in the forced experiments, there was never a case in which the $500 \mathrm{mb}$-level temperatures did not register a statistically significant $(p<0.1)$ trend (i.e. a trend detectable with a simple linear regression model). The minimum $\mathrm{p}$ value of approximately 0.08 occurred in the single case in which the significance was not greater than $99 \%$.

- It was more likely that the surface warmed relative to the mid-troposphere under control simulations than under forced simulations.

- At no time, in any model realization, forced or unforced, did any model simulate the presently observed situation of a large and highly significant surface warming accompanied with no warming whatsoever aloft.

A revised estimate of tropospheric temperature trends (Mears et al. 2003), if robust, serves to reduce the magnitude of the discrepancy, but it does not change the overall conclusions of this study. However, Christy et al. (2003) have argued through a detailed error analysis that the Mears et al. (2003) warming trend is likely too large. Such a conclusion mirrors that of Pielke et al. (1998a,b). Conversely, Santer et al. (2003) indicate that the spatial pattern of warming in the Mears et al. (2003) time series is more consistent with model simulations. However, we believe caution is in order when assessing regional patterns of climate change in models which neglect some processes, such as land-cover change, which can have large regional effects (Chase et al. 2001, Pielke et al. 2002) and are forced by other processes, such as the effect of sulfate aerosols, which are described as having 'low' levels of scientific understanding (IPCC 2001) and which are possibly quite erroneous (Anderson et al. 2003). A National Academy Report (2001) also indicated that at least part of the disparity between surface and free troposphere was likely to be real and suggested that uncertainties in forcing might be responsible for some of the remainder. This does not appear to be the case.

These results imply that model variability and uncertainty in applied forcings cannot produce the recently observed tropospheric temperature characteristics. This interpretation is consistent with Santer et al. (1998), who used more comprehensive but more uncertain forcings, and with Hegerl \& Wallace (2002), who found that observed changes in lapse rate cannot be attributed to natural variability and that such changes were highly unlikely in a single coupled model with more comprehensive estimates of human climatic forcing.

The disparity between model simulations under these assumptions and observed climatic shifts may be 
an indication that additional forcing combinations are necessary, that internal variability is improperly simulated or that inadequately simulated feedback mechanisms (perhaps in the vertical distribution of cloud or water vapor) are at work. Because accelerated warming aloft, particularly in the tropics, is intimately tied with convective processes, such a discrepancy might also result from the systematic overestimation of energy transfer aloft by convective parametrizations.

While we cannot assess here the degree to which the above possibilities are responsible for the inability of recent climate-change simulations to reproduce recent observations, it is important to note that many of the conclusions from the IPCC (2001) and the National Assessment Synthesis Team (2001) are derived from similar models and forcing assumptions as those discussed here. Significant errors in the simulations of globally averaged tropospheric temperature structure indicate likely errors in tropospheric water-vapor content and therefore total greenhouse-gas forcing, precipitable water and convectively forced large-scale circulations. Such errors argue for extreme caution in applying simulation results to future climate-change assessment activities and to attribution studies (e.g. Zwiers \& Zhang 2003) and call into question the predictive ability of recent generation model simulations, the most rigorous test of any hypothesis.

Acknowledgements. Support was provided by the Colorado Agricultural Experiment Station and NOAA under grant NA06GP0569 (to X.Z.). We thank Roy Jenne, Madhav Khandekar and 3 anonymous referees for their very useful comments.

\section{LITERATURE CITED}

Anderson LA, Charlson RJ, Schwartz SE, Knutti R, Boucher O, Rodhe H, Heintzenberg J (2003) Climate forcing by aerosols: a hazy picture. Science 300:1103-1104

Chase TN, Pielke Sr RA, Zhao M, Pitman AJ, Kittel TGF, Running SR, Nemani RR (2001) The relative climatic effects of landcover change and elevated carbon dioxide combined with aerosols: a comparison of model results and observations. J Geophys Res 106:31685-31691

Christy JR, Spencer RW, Braswell WD (2000) MSU tropospheric temperatures: dataset construction and radiosonde comparisons. J Atmos Ocean Technol 17:1153-1170

Christy JR, Spencer RW, Norris WB, Braswell WD (2003) Error estimates of version 5.0 of MSU-AMSU bulk atmospheric temperatures. J Atmos Ocean Tech 20:613-629

Delworth TL, Stouffer RJ, Dixon KW, Spelman MJ, Knutson TR, Broccoli AJ, Kushner PJ, Wetherald RT (2002) Review of simulation of climate variability and change by the GFDL R30 coupled climate model. Clim Dyn 19:555-574

Flato GM, Boer GJ (2001) Warming asymmetry in climate change simulations. Geophys Res Lett 28:195-198

Flato GM, Boer GJ, Lee WG, McFarlane NA, Ramsden D, Reader MC, Weaver AJ (2000) The Canadian Centre for Climate Modelling and Analysis global coupled model and its climate. Clim Dyn 16:451-467
Hegerl GC, Wallace JM (2002) Influence of patterns of climate variability on the difference between satellite and surface temperature trends. J Clim 15:2412-2428

IPCC (1995) Second assessment report: climate change 1995. The science of climate change. Houghton JT, Meira Filho LG, Callender BA, Harris N, Kattenberg A, Maskell K (eds) Cambridge University Press, Cambridge

IPCC (2001) Third assessment report: climate change 2001. The scientific basis. Houghton JT, Ding Y, Griggs DJ, Noguer M, van der Linden PJ, Xiaosu D (eds) Cambridge University Press, Cambridge

Jones PD, Osborn TJ, Briffa KR, Folland CK, Horton EB, Alexander LV, Parker DE, Rayner NA (2001) Adjusting for sampling density in grid box land and ocean surface temperature time series. J Geophys Res 106:3371-3380

Kalnay E and 21 others (1996) The NCEP/NCAR 40-year reanalysis project. Bull Am Meteorol Soc 77:437-471

Langner J, Rodhe H (1991) A global three-dimensional model of the tropospheric sulfur cycle. J Atmos Chem 13: $225-263$

Mears CA, Schabel MC, Wentz FJ (2003) A reanalysis of the MSU channel 2 tropospheric temperature record. J Clim 16:3650-3664

Mitchell JFB, Davis RA, Ingram WJ, Senior CA (1995) On surface temperatures, greenhouse gasses and aerosols: models and observations. J Clim 8:2364-2386

National Academy Report (2000) Reconciling observations of global temperature change. National Academy Press, Washington, DC

National Assessment Synthesis Team (2001) Climate change impacts on the United States. Cambridge University Press, Cambridge, UK

Pielke RA, Eastman JE, Chase TN, Knaff J, Kittel TGF (1998a) 1973-1996 trends in depth-averaged tropospheric temperature. J Geophys Res 103:16927-16933

Pielke RA, Eastman JE, Chase TN, Knaff J, Kittel TGF (1998b) Correction to '1973-1996 trends in depth-averaged tropospheric temperature'. J Geophys Res 103:28909-28911

Pielke RA Sr, Marland G, Betts R, Chase TN, Eastman JL, Niles JO, Niyogi D, Running SW (2002) The influence of land-use change and landscape dynamics on the climate system-relevance to climate change policy beyond the radiative effect of greenhouse gasses. Phil Trans $\mathrm{R}$ Soc Lond A 360:1705-1719

Roeckner E, Bengtsson L, Feitcher J, Lelieveld J, Rodhe H (1999) Transient climate change simulations with a coupled atmosphere-ocean GCM including the tropospheric sulfur cycle. J Clim 12:3004-3032

Russell GL, Miller JR, Rind D, Ruedy RA, Schmidt GA, Sheth S (2000) Comparison of model and observed regional temperature changes during the past 40 years. J Geophys Res 105:14891-14898

Santer BD, Wigley TML, Gaffen DJ, Bengtsson L and 9 others (1998) Interpreting differential temperature trends at the surface and in the lower troposphere. Science 287: 1227-1232

Santer BD, Wigley TML, Meehl GA, Wehner MF and 10 others (2003) Influence of satellite data uncertainties on the detection of externally forced climate change. ScienceExpress, 1 May edn. Available at www.scienceexpress.org

Sterin AM (2001) Tropospheric and lower stratospheric temperature anomalies based on global radiosonde network data. In: Trends online: a compendium of data on global change. Carbon Dioxide Information Analysis Center, Oak Ridge National Laboratory, US Department of Energy, Oak Ridge, TN

Zwiers FW, Zhang X (2003) Towards regional-scale climate change detection. J Clim 16:793-797 